\title{
Article
}

\section{Preparation of core-crosslinked linear- dendritic copolymer micelles with enhanced stability and their application for drug solubilisation}

Zhou, Zhengyuan, Forbes, Robert T. and D'Emanuele, Antony

Available at http://clok.uclan.ac.uk/17481/

Zhou, Zhengyuan ORCID: 0000-0002-6804-3897, Forbes, Robert T. ORCID: 0000-0003-3521-4386 and D'Emanuele, Antony (2017) Preparation of corecrosslinked linear-dendritic copolymer micelles with enhanced stability and their application for drug solubilisation. International Journal of

Pharmaceutics, 523 (1). pp. 260-269. ISSN 0378-5173

It is advisable to refer to the publisher's version if you intend to cite from the work. http://dx.doi.org/10.1016/j.ijpharm.2017.03.032

For more information about UCLan's research in this area go to http://www.uclan.ac.uk/researchgroups/ and search for <name of research Group>.

For information about Research generally at UCLan please go to http://www.uclan.ac.uk/research/

All outputs in CLoK are protected by Intellectual Property Rights law, including Copyright law. Copyright, IPR and Moral Rights for the works on this site are retained by the individual authors and/or other copyright owners. Terms and conditions for use of this material are defined in the policies page. 
2 Preparation of core-crosslinked linear-dendritic copolymer micelles with enhanced stability and their application for drug solubilisation

$6 \quad{ }^{a}$ School of Pharmacy and Biomedical Sciences, University of Central Lancashire, Preston PRI

$7 \quad 2 H E, U K$

$8 \quad{ }^{\mathrm{b}}$ Leicester School of Pharmacy, De Montfort University, The Gateway, Leicester LE1 9BH, UK

10 *Corresponding author. Tel.: +44(0) 177289 5803, fax: +44(0)7092 030763

11 Email address: ZZhou2@uclan.ac.uk

15 Keywords: Linear-dendritic copolymers, Thiol-ene reaction, Micellisation, Core-crosslinking,

16 Charged aerosol detection, Drug solubilisation. 


\section{Abstract}

In this study we explore the preparation of core-crosslinked micelles of linear-dendritic

22 methoxy-poly(ethylene glycol) (MPEG)-co-poly(ester-sulfide) (PES) polymers to improve the

23 stability of such polymeric micelle systems against premature disintegration and drug release. A

24 series of MPEG-PES copolymers were synthesised via stepwise reactions of acetylation and

25 thiol-ene photoreaction. Surface tension measurement showed that the copolymers with ethenyl

26 surface groups could self-associate in dilute aqueous solutions to form micelles. Crosslinking

27 within the micelle cores in the presence of dithioerythritol (DTT) linker was initiated under UV

28 radiation. The formation of core-crosslinked micelles was confirmed by HPLC in combination

29 with charged aerosol detection (CAD). The copolymers were found to readily hydrolyse under

30 acidic conditions due to the ester-containing dendrons. Drug solubilisation capacities of the

31 micellar solutions were determined using griseofulvin as a poorly water-soluble model drug. The

32 solubility of griseofulvin showed a 10-fold enhancement in $1 \% \mathrm{w} / \mathrm{v}$ micelle solution and

33 increased with the concentration of the copolymers. Drug release studies indicated that a more

34 sustained release of griseofulvin was achieved for the core-crosslinked micelles compared to the

35 non-crosslinked micelles, attributable to greater stability of the crosslinked core structure. The

36 findings of this study present a new pathway towards developing biodegradable polymeric

37 nanocarriers. 


\section{Introduction}

It is known that more than half of potentially useful drug candidates fail to progress to

44 formulation development due to their low solubility in physiological aqueous environment. The

45 poor solubility results in limited gastrointestinal absorption and poor bioavailability. Numerous

46 methods have been investigated in recent decades to improve the water solubility of lipophilic

47 drugs, e.g. control of $\mathrm{pH}$, chemical or physical modification, conjugation with polymeric carriers,

48 and encapsulation in nanoparticles/micelles (Torchilin, 2001; Williams et al., 2013). Polymeric

49 micelles, which can enhance the solubility of drugs by encapsulating drug molecules within the

50 micelle core, have been investigated extensively for pharmaceutical applications (Kwon, 2003;

51 Adams et al., 2003; Attwood et al., 2007). The hydrophobic micelle core provides a suitable

52 domain for the incorporation of a lipophilic drug. The stability and bioavailability of the drug

53 encapsulated is improved due to the unfavoured access to solvents and inert nature of the micelle

54 core. The hydrophilic corona can reduce nonspecific uptake by the reticuloendothelial system

55 and prolong the circulation time of drugs in the body (Gaucher et al., 2010).

56 Although polymeric micelles are thermodynamically stable, dissociation of the micelles as

57 a result of dilution in biological fluids or under solvent changes is still a concern, leading to

58 premature release of drug. Numerous attempts have been made to improve the stability of

59 polymeric micelle systems. Among the most promising strategies is the introduction of a

60 crosslinking structure by covalently connecting polymer chains in the micelle (O'Reilly et al.,

61 2006; Read and Armes, 2007). The monomers with functional groups are designed and utilised

62 to synthesise a specific block of amphiphilic block copolymer. After micellisation the functional

63 groups undergo crosslinking and thus provide reinforcement to the micellar structure. Various 
64 methods have been developed to facilitate the crosslinking of block copolymers (Nostrum, 2011), 65 e.g. free radical polymerisation (Hu et al., 2009; Wu et al., 2012), addition of bifunctional

66 reagents (Liu et al., 2002; Yue et al., 2012), photochemical reaction (Kim and Youk, 2009;

67 Huang et al., 2016), and disulfide reduction (Li et al, 2015). Zhong and co-workers developed core-crosslinked biodegradable micelles based on poly(ethylene glycol)-poly(2,4,6-

69 trimethoxybenzylidene-pentaerythritol carbonate-co-pyridyl disulfide carbonate) [PEG-

70 P(TMBPEC-co-PDSC)] copolymers (Chen et al., 2015). The hydrophobic core-forming PDSC

71 units contained disulfide bonds that readily crosslinked under the presence of dithioerythritol by

72 the thiol-disulfide exchange reaction. In vitro release studies showed that sustained release was

73 achieved for the crosslinked micelles under physiological conditions with ca. $19.9 \%$ of

74 doxorubicin (DOX) released in $24 \mathrm{~h}$. The release of DOX was accelerated in acidic solutions or

75 in the presence of the biological reducing agent glutathione. The synthesis of amphiphilic

76 poly(N-acroyloxysuccinimide)-b-poly(N-isopropylacrylamide)-b-poly( $\varepsilon$-caprolactone) triblock

77 copolymer was reported by Zhang and co-workers using reversible addition fragmentation chain

78 transfer and ring-opening polymerisation (Quan et al., 2011). The hydrophilic poly(N-

79 acroyloxysuccinimide) blocks containing reactive NHS ester groups formed the micelle corona

80 and crosslinked via reaction with cystamine, a bifunctional linker. It was found that media

81 change had no impact on the micelle shape due to the shell-crosslinking. Xiong et al. designed

82 and synthesised the poly (ethylene glycol)-b-poly(acryloyl carbonate)-b-poly(D,L-lactide) (PEG-

83 PAC-PLA) and folate-PEG-PLA block copolymers by sequential ring-opening polymerisation

84 (Xiong et al., 2011). The copolymers formed mixed micelles with a hydrophobic PLA core, a

85 hydrophilic PEG corona and an interfacial PAC layer. The acrylic side groups of the PAC blocks

86 underwent radical polymerisation under UV radiation and thus formed a crosslinked structure 
87 between the micelle core and shell. The crosslinked micelles demonstrated enhanced colloidal

88 stability and smaller size than non-crosslinked micelles. High drug loading efficiencies and

89 sustained release of paclitaxel were obtained in dilute micellar solutions.

90 Dendrimers are a class of hyperbranched macromolecules with a high degree of uniformity

91 and monodispersity, and multiple surface functional groups (Esfand and Tomalia, 2001;

92 D'Emanuele and Attwood, 2005). Drug molecules can be encapsulated within the dendritic

93 structure or covalently attached to the surface functional groups (D'Emanuele et al., 2013).

94 Linear-dendritic block copolymers, comprising a dendrimer or dendron conjugated to a linear

95 polymer chain, have attracted considerable attention for their applications in drug solubilisation

96 and delivery in the last two decades (Whitton and Gillies, 2015). Gitsov and Fréchet first

97 explored the synthesis of poly(ethylene glycol) (PEG)-dendritic poly(benzyl ether) copolymers

98 (Gitsov and Fréchet, 1993). It was found that the micellisation behavior was dependent on

99 concentration and dendrimer generation. In our earlier study we synthesised triblock linear-

100 dendritic-linear copolymers comprising two poly(oxybutylene)-b-poly(oxyethylene) (BE)

101 copolymers conjugated to a full generation PAMAM dendrimer (Zhou et al., 2009). Significant

102 solubility enhancement of paclitaxel was achieved in dilute micellar solutions of the copolymers

103 (Zhou et al., 2013). Recently, core crosslinking within the linear-dendritic copolymer micelles

104 has been exploited by several groups to prepare stimuli-responsive micelle systems and enhance

105 their stability. Lam and co-workers synthesised linear-dendritic copolymers comprising a

106 hydrophilic PEG and a thiolated poly(L-Lysine) dendron surface functioned with cholic acids (Li

107 et al., 2011). The thiol groups in the dendrons were then oxidised to form disulfide linkage in the

108 micelle core. The core-crosslinked micelles had improved stability in human plasma and in

109 sodium dodecyl sulfate solution. The release study showed that the release of paclitaxel from the 
110 crosslinked micelles was more sustained but accelerated in the presence of glutathione due to the

111 reduction of disulfide bonds. Chen and co-workers have designed and prepared liner-dendritic

112 copolymers consisted of PEG and a PAMAM dendron (Zhang et al., 2014). The surface amino

113 groups of the PAMAM dendron were then partially conjugated with DOX and lipoic acid. After

114 micellisation the lipoic acid moieties in the micelle core were crosslinked via the thiol-disulfide

115 exchange reaction with DTT in borate buffer. The crosslinked micelles were more stable against

116 dilution and high salt concentration. The release of DOX from the crosslinked micelles was slow

117 under neutral conditions but the release rate was increased in acidic solution and in the presence

118 of glutathione due to hydrolysis and disulfide reduction.

119 Poly(ester-sulfide) dendrimers have been prepared by Hawker and co-workers via a

120 combination of thiol-ene photochemistry and esterification by 4-pentenoic anhydride. Thiol-ene

121 photochemistry has been proved to be efficient for free radical addition of thiol with ethenyl

122 group in the presence of a photo initiator. Sedaghat-Herati and co-workers synthesised linear-

123 dendritic copolymers of methoxy-poly(ethylene glycol) (MPEG) and poly(ester-sulfide) (PES)

124 dendron via acrylation by acryloyl chloride and thiol-ene addition with thioglycerol (Fury et al,

125 2009). However the thiol-ene reaction was completed via an ionic mechanism (Michael addition).

126 Recent work from the same group employed thiol-ene photochemistry and esterification with 4-

127 pentenoyl chloride to prepare MPEG-PES copolymers (Fury et al., 2013). Up to generation 3.5

128 PES dendron was constructed to the hydroxyl end of MPEG chain. In the present study we

129 explored the core-crosslinking and stability study of MPEG-PES copolymer micelles and

130 investigated their applications for drug solubilisation and sustained release. This work reported

131 the synthesis and characterisation of linear-dendritic MPEG-PES block copolymer via stepwise

132 reactions of acrylation by acryloyl chloride and thiol-ene photochemistry. The core-crosslinked 
133 micelles were prepared by thiol-ene free radical addition in the presence of DTT and Irgacure

1342959 photoinitiator. The formation and stability of the crosslinked micelles were studied using

135 the CAD-HPLC technique. The solubilisation of griseofulvin in the copolymer micellar solutions

136 was investigated and the drug release profiles were determined by UV assay.

138 2. Experimental

139

140 2.1. Materials

141

Poly(ethylene glycol) methyl ether (MPEG) (MW 5000), acryloyl chloride, triethylene

143 amine (TEA), 1-thioglycerol, anhydrous chloroform, 2,2-dimethoxy-2-phenylacetophenone

144 (DMPA), 1,4- dithioerythritol (DTT), 2-Hydroxy-4'-(2-hydroxyethoxy)-2-methylpropiophenone

145 (Irgacure 2959), Sephadex ${ }^{\circledR}$ LH-20 were purchased from Sigma-Aldrich (UK). Spectra/Por ${ }^{\circledR}$

146 Dialysis Membrane (MWCO 3,500) was from Spectrum Laboratories Inc. (UK) and Slide-A-

147 Lyzer $^{\circledR}$ MINI Dialysis unit (MWCO 2,000) was purchased from Thermo Scientific Inc. NMR

148 grade chloroform-d and deuterium oxide were from Goss Scientific Instruments Ltd.

149 Griseofulvin (97\%) was purchased from ACROS Organics UK.

151 2.2. Synthesis and characterisation of MPEG-poly(ester-sulfide) copolymers

The MPEG-poly(ester-sulfide) copolymers were synthesised via acrylation and thiol-ene

154 photochemical reaction. In this paper the MPEG-poly(ester-sulfide) copolymers are noted as

155 MPEG-DEN-G $\mathrm{G}_{\mathrm{X}}(\mathrm{X}$ means dendron generation) for simplicity. Half generation dendrons are 
156 terminated with ethenyl groups while full generation dendrons have hydroxyl surface groups.

157 Thiol-ene photochemical reactions were performed by UV cross-linker, UVItec Ltd (365 nm,

$15899.99 \mathrm{~J} \mathrm{~cm}^{-2}$ ). The copolymers were characterised by ${ }^{1} \mathrm{H}$ and ${ }^{13} \mathrm{C}$ NMR spectroscopy (Bruker

159 Avance 400, Bruker, Coventry, UK).

160

Synthesis of half generation MPEG-DEN (acrylation)

162

$1 \mathrm{mmol}$ of MPEG (or MPEG-DEN-OH ${ }_{\mathrm{X}}$ ) and excess acryloyl chloride (molar ratio of

164 carbonyl chloride $:$ hydroxyl $=1.2: 1$ ) was dissolved in $100 \mathrm{ml}$ anhydrous chloroform at $25^{\circ} \mathrm{C}$.

165 Triethylene amine (equal moles to acryloyl chloride) in $5 \mathrm{ml}$ chloroform was added drop-wise in

166 the MPEG solution and stirred at $30{ }^{\circ} \mathrm{C}$ for $48 \mathrm{~h}$. The mixture was dried under vacuum,

167 redissolved in $25 \mathrm{ml}$ chloroform, and then suspended in $500 \mathrm{ml}$ diethyl ether. The precipitant was

168 filtered and dried under vacuum. The crude product was dissolved in chloroform and purified by

169 Sephadex LH-20 column (methanol:chloroform 60:40). Product with a yield of over $70 \%$ was

170 recovered after evaporating the solvent.

171

172

Synthesis of full generation MPEG-DEN (thiol-ene photoreaction)

173

174

MPEG-acrylates (or MPEG-DEN-ene ${ }_{\mathrm{X}}$ ) $(1 \mathrm{mmol})$ and DMPA (12.2 mg, $\left.0.1 \mathrm{mmol}\right)$ were

175 dissolved in a mixed solvent of $50 \mathrm{ml}$ chloroform and $5 \mathrm{ml}$ methanol. Excess 1-thioglycerol

176 (molar ratio of thiol : acrylate $=2: 1$ ) was added to the solution. The solution was irradiated

177 under UV light for $60 \mathrm{~min}$. The mixture was precipitated into $500 \mathrm{ml}$ diethyl ether and then 
178 filtered and dried under vacuum. The crude product was redissolved in $30 \mathrm{ml}$ chloroform,

179 washed with brine twice and then dried under vacuum.

180

NMR Characterisation:

182

MPEG: ${ }^{1} \mathrm{H}$ NMR $\left(\mathrm{CDCl}_{3}\right): 3.38\left(\mathrm{~s}, \mathrm{CH}_{3} \mathrm{O}-\right), 3.45-3.95\left(\mathrm{~m},-\mathrm{OCH}_{2} \mathrm{CH}_{2} \mathrm{O}-\right.$, backbone $) .{ }^{13} \mathrm{C}$

183

$\mathrm{NMR}\left(\mathrm{CDCl}_{3}\right): 58.72\left(\mathrm{CH}_{3} \mathrm{O}-\right), 61.29\left(-\mathrm{CH}_{2} \mathrm{CH}_{2} \mathrm{OH}\right), 70.48\left(-\mathrm{OCH}_{2} \mathrm{CH}_{2} \mathrm{O}-\right), 71.62$

184

$\left(\mathrm{CH}_{3} \mathrm{OCH}_{2}-\right), 72.27\left(-\mathrm{CH}_{2} \mathrm{CH}_{2} \mathrm{OH}\right)$.

185

186

MPEG-DEN-ene (G0.5, MPEG-acrylate): ${ }^{1} \mathrm{H}$ NMR $\left(\mathrm{CDCl}_{3}\right): 3.38$ (s, $\left.\mathrm{CH}_{3} \mathrm{O}-\right), 3.45-3.95$

187

(m, $-\mathrm{OCH}_{2} \mathrm{CH}_{2} \mathrm{O}-$ ), 4.32 (t, $-\mathrm{CH}_{2} \mathrm{OCO}-$ ), 5.83, 5.86 (dd, $-\mathrm{CH}=\mathrm{CH}_{2}$ cis), 6.12-6.19 (q, -

188

$\left.\mathrm{CH}=\mathrm{CH}_{2}\right), 6.41,6.45\left(\mathrm{dd},-\mathrm{CH}=\mathrm{CH}_{2}\right.$ trans $) .{ }^{13} \mathrm{C} \mathrm{NMR}\left(\mathrm{CDCl}_{3}\right): 58.98\left(\mathrm{CH}_{3} \mathrm{O}-\right), 63.63(-$

189

$\left.\mathrm{CH}_{2} \mathrm{CH}_{2} \mathrm{OCO}-\right), 69.05$ (- $\left.\mathrm{CH}_{2} \mathrm{CH}_{2} \mathrm{OCO}-\right), 70.50$ (- $\left.\mathrm{OCH}_{2} \mathrm{CH}_{2} \mathrm{O}-\right), 71.88\left(\mathrm{CH}_{3} \mathrm{OCH}_{2}-\right), 128.25$ (-

190

$\left.\mathrm{CO}-\mathrm{CH}=\mathrm{CH}_{2}\right), 130.95\left(-\mathrm{CO}-\mathrm{CH}=\mathrm{CH}_{2}\right), 166.04(-\mathrm{OCO}-)$.

191

192

193

$2.85\left(\mathrm{t},-\mathrm{CH}_{2} \mathrm{CH}_{2} \mathrm{SCH}_{2}-\right), 3.38\left(\mathrm{~s}, \mathrm{CH}_{3} \mathrm{O}-\right), 3.45-3.95\left(\mathrm{~m},-\mathrm{OCH}_{2} \mathrm{CH}_{2} \mathrm{O}-,-\mathrm{CH}(\mathrm{OH})-,-\mathrm{CH}_{2} \mathrm{OH}\right)$,

$4.25\left(\mathrm{t},-\mathrm{CH}_{2} \mathrm{OCO}-\right) .{ }^{13} \mathrm{C} \mathrm{NMR}\left(\mathrm{CDCl}_{3}\right): 27.40\left(-\mathrm{COCH}_{2} \mathrm{CH}_{2} \mathrm{~S}-\right), 34.76\left(-\mathrm{COCH}_{2} \mathrm{CH}_{2} \mathrm{~S}-\right)$,

195

$35.53\left(-\mathrm{SCH}_{2} \mathrm{CH}<\right), 59.00\left(\mathrm{CH}_{3} \mathrm{O}-\right), 63.81\left(-\mathrm{CH}_{2} \mathrm{CH}_{2} \mathrm{OCO}-\right), 65.27\left(-\mathrm{CH}_{2} \mathrm{OH}\right), 69.02(-$

196

$\left.\mathrm{CH}_{2} \mathrm{CH}_{2} \mathrm{OCO}-\right), 70.50\left(-\mathrm{OCH}_{2} \mathrm{CH}_{2} \mathrm{O}-,-\mathrm{CH}(\mathrm{OH})-\right), 71.88\left(\mathrm{CH}_{3} \mathrm{OCH}_{2}-\right), 171.84(-\mathrm{OCO}-)$.

197

198

MPEG-DEN-ene 2 (G1.5): ${ }^{1} \mathrm{H}$ NMR $\left(\mathrm{CDCl}_{3}\right): 2.60-2.90\left(\mathrm{~m},-\mathrm{OCOCH}_{2}-,-\mathrm{SCH}_{2} \mathrm{CH}(\mathrm{OH})-\right.$,

199

$-\mathrm{CH}_{2} \mathrm{CH}_{2} \mathrm{SCH}_{2}-$ ), 3.38 (s, $\mathrm{CH}_{3} \mathrm{O}-$ ) , 3.45-3.95 (m, $-\mathrm{OCH}_{2} \mathrm{CH}_{2} \mathrm{O}-$-), 4.10-4.50 (m, - $\mathrm{CH}_{2} \mathrm{OCO}-$ ),

200

5.10-5.40 (m, >CHOCO-), 5.83-5.90 (m, $\left.-\mathrm{CH}=\mathrm{CH}_{2} \mathrm{cis}\right), 6.05-6.19\left(\mathrm{~m},-\mathrm{CH}=\mathrm{CH}_{2}\right), 6.35-6.50$ 
$201\left(\mathrm{~m},-\mathrm{CH}=\mathrm{CH}_{2}\right.$ trans). ${ }^{13} \mathrm{C} \mathrm{NMR}\left(\mathrm{CDCl}_{3}\right): 27.47\left(-\mathrm{COCH}_{2} \mathrm{CH}_{2} \mathrm{~S}-\right), 32.23\left(-\mathrm{SCH}_{2} \mathrm{CH}<\right), 34.58(-$ $\left.202 \mathrm{COCH}_{2} \mathrm{CH}_{2} \mathrm{~S}-\right), 58.95\left(\mathrm{CH}_{3} \mathrm{O}-\right), 63.64\left(>\mathrm{CHCH} \mathrm{HCOCH}_{2} \mathrm{OCO}, 63.79\left(-\mathrm{CH}_{2} \mathrm{CH}_{2} \mathrm{OCO}-\right), 68.97(-\right.$ $\left.203 \mathrm{CH}_{2} \mathrm{CH}_{2} \mathrm{OCO}-\right), 70.50\left(-\mathrm{OCH}_{2} \mathrm{CH}_{2} \mathrm{O}-\right), 71.88\left(\mathrm{CH}_{3} \mathrm{OCH}_{2}-\right), 127.79,127.91\left(-\mathrm{CO}-\mathrm{CH}=\mathrm{CH}_{2}\right)$, $204131.45,131.66\left(-\mathrm{CO}-\mathrm{CH}=\mathrm{CH}_{2}\right), 165.16,165.47\left(-\mathrm{OCOCH}=\mathrm{CH}_{2}\right), 171.48\left(-\mathrm{OCOCH}_{2}-\right)$. 205

MPEG-DEN-OH ${ }_{4}(\mathrm{G} 2):{ }^{1} \mathrm{H}$ NMR $\left(\mathrm{CDCl}_{3}\right): 2.50-2.95\left(\mathrm{~m},-\mathrm{OCOCH}_{2}-,-\mathrm{SCH}_{2} \mathrm{CH}<,-\right.$ $\left.\mathrm{CH}_{2} \mathrm{CH}_{2} \mathrm{SCH}_{2}-\right), 3.38$ (s, $\left.\mathrm{CH}_{3} \mathrm{O}-\right)$, 3.40-3.95 (m, $\left.-\mathrm{OCH}_{2} \mathrm{CH}_{2} \mathrm{O}-,-\mathrm{CH}(\mathrm{OH})-,-\mathrm{CH}_{2} \mathrm{OH}\right), 4.10-$ 4.50 (m, $\left.-\mathrm{CH}_{2} \mathrm{OCO}-\right), 5.10-5.40$ (m, >CHOCO-$) .{ }^{13} \mathrm{C} \mathrm{NMR}\left(\mathrm{CDCl}_{3}\right): 27.38\left(-\mathrm{COCH}_{2} \mathrm{CH}_{2} \mathrm{~S}-\right)$, $32.13\left(-\mathrm{SCH}_{2} \mathrm{CH}(\mathrm{O}) \mathrm{CH}_{2}-\right), 34.54\left(-\mathrm{COCH}_{2} \mathrm{CH}_{2} \mathrm{~S}-\right), 35.42\left(-\mathrm{SCH}_{2} \mathrm{CH}(\mathrm{OH}) \mathrm{CH}_{2}-\right), 58.96$ $\left(\mathrm{CH}_{3} \mathrm{O}-\right), 63.82\left(>\mathrm{CHCH}_{2} \mathrm{OCO}-,-\mathrm{CH}_{2} \mathrm{CH}_{2} \mathrm{OCO}-\right), 65.20\left(-\mathrm{CH}_{2} \mathrm{OH}\right), 68.94\left(-\mathrm{CH}_{2} \mathrm{CH}_{2} \mathrm{OCO}-\right)$, $70.50\left(-\mathrm{OCH}_{2} \mathrm{CH}_{2} \mathrm{O}-,-\mathrm{CH}(\mathrm{OH})-\right), 71.84\left(\mathrm{CH}_{3} \mathrm{OCH}_{2}-\right), 171.17,171.40,171.62\left(-\mathrm{OCOCH}_{2}-\right)$. 212

MPEG-DEN-ene ${ }_{4}(\mathrm{G} 2.5):{ }^{1} \mathrm{H}$ NMR $\left(\mathrm{CDCl}_{3}\right): 2.50-3.00\left(\mathrm{~m},-\mathrm{OCOCH}_{2}-,-\mathrm{SCH}_{2} \mathrm{CH}<,-\right.$ $\left.\mathrm{CH}_{2} \mathrm{CH}_{2} \mathrm{SCH}_{2}-\right), 3.38$ (s, $\left.\mathrm{CH}_{3} \mathrm{O}-\right)$, 3.45-3.95 (m, $\left.-\mathrm{OCH}_{2} \mathrm{CH}_{2} \mathrm{O}-\right), 4.10-4.50$ (m, $\left.-\mathrm{CH}_{2} \mathrm{OCO}-\right)$, $216\left(\mathrm{~m},-\mathrm{CH}=\mathrm{CH}_{2}\right.$ trans). ${ }^{13} \mathrm{C} \mathrm{NMR}\left(\mathrm{CDCl}_{3}\right): 27.40\left(-\mathrm{COCH}_{2} \mathrm{CH}_{2} \mathrm{~S}-\right), 32.18\left(-\mathrm{SCH}_{2} \mathrm{CH}(\mathrm{O}) \mathrm{CH}_{2}-\right)$, $21734.56\left(-\mathrm{COCH}_{2} \mathrm{CH}_{2} \mathrm{~S}-\right), 58.98\left(\mathrm{CH}_{3} \mathrm{O}-\right), 63.65\left(>\mathrm{CHCH} \mathrm{H}_{2} \mathrm{OCOCH}=\right), 63.81\left(>\mathrm{CHCH}_{2} \mathrm{OCO}-,-\right.$ $\left.218 \mathrm{CH}_{2} \mathrm{CH}_{2} \mathrm{OCO}-\right), 68.98\left(-\mathrm{CH}_{2} \mathrm{CH}_{2} \mathrm{OCO}-\right), 70.50\left(-\mathrm{OCH}_{2} \mathrm{CH}_{2} \mathrm{O}-\right), 71.88\left(\mathrm{CH}_{3} \mathrm{OCH}_{2}-\right), 127.78$, $219127.90\left(-\mathrm{CO}-\mathrm{CH}=\mathrm{CH}_{2}\right), 131.52,131.74\left(-\mathrm{CO}-\mathrm{CH}=\mathrm{CH}_{2}\right), 165.21,165.52\left(-\mathrm{OCOCH}=\mathrm{CH}_{2}\right)$, $220170.83,171.10,171.53\left(-\mathrm{OCOCH}_{2}-\right)$.

221

222 Gel permeation chromatography (GPC) was used to characterise the MPEG-DEN 223 copolymers. The GPC system was an Agilent 1260 Infinity with triple detectors and two Agilent 
224 PLgel Mixed-D columns. Dichloromethane was used as eluent at a flow rate of $1 \mathrm{ml} \mathrm{min}^{-1}$. The 225 system was calibrated with Agilent EasiVial PS-M and PS standards ( $\left.M_{p} 217,900\right)$.

226

227 2.3. CMC measurement

228

The critical micelle concentrations (CMC) of the MPEG-poly(ester-sulfide) copolymers at

$23020^{\circ} \mathrm{C}$ were measured by surface tension measurement using the pendant drop method. An

231 FTA1000 video system (First Ten Ångstroms Inc) was used to visualise drops formed on the tip 232 of a 20-gauge stainless-steel needle (aperture 22, brightness and contrast 50\%). The tip width of 233 the needle was measured to perform a calibration of the video camera's magnification. Surface

234 tension of aqueous polymer solution ranging in concentration from 0.0001 to $2 \% \mathrm{w} / \mathrm{v}$ was 235 calculated via drop-shape analysis; measurements were repeated ten times and the results 236 averaged. The standard deviation of the drop-shape analysis was approximately $\pm 0.5 \mathrm{mN} \mathrm{m}^{-1}$ 237 and the measurement error was less than $5 \%$.

\subsection{Preparation and stability study of core-crosslinked micelles}

$1 \mathrm{~g}(0.175 \mathrm{mmol})$ of MPEG-DEN-G2.5 was dissolved in $25 \mathrm{~mL}$ of distilled water. $62 \mathrm{mg}$

242 (0.4 mmol) of DTT and $4.5 \mathrm{mg}(0.02 \mathrm{mmol})$ of Irgacure 2959 were added in the solution and

243 stirred at RT for $2 \mathrm{~h}$. The solution was irritated under UV ( $365 \mathrm{~nm})$ for $1 \mathrm{~h}$. The completion of

244 crosslinking was assessed by ${ }^{1} \mathrm{H}$ NMR. The solution was dialysised again distilled water

245 (MWCO 3500) overnight and then lyophilized to recover the core-crosslinked micelles. 
The crosslinking was investigated by HPLC, using an Agilent 1100 Series HPLC system

247 equipped with a Luna $5 \mu \mathrm{m}, \mathrm{C} 18$ column (250 mm x $4.6 \mathrm{~mm}$ ) (Phenomenex, Cheshire, UK) at

$24840{ }^{\circ} \mathrm{C}$. The mobile phase was MeOH:TFA $(0.05 \% \mathrm{w} / \mathrm{v})(80: 20)$, with a flow rate of $1.0 \mathrm{ml} \mathrm{min}^{-1}$,

249 and Corona Plus CAD detection (ESA) with gas pressure of 35 psi.

$2501 \% \mathrm{w} / \mathrm{v}$ solutions of the crosslinked and non-crosslinked copolymers were prepared in

251 phosphate buffer (0.067M, pH 7.4) and hydrochloric acid buffer (0.085M, pH 1.2) and incubated

252 at $37{ }^{\circ} \mathrm{C}$ for 48 and $24 \mathrm{~h}$ respectively. The solutions were diluted 5 times with $80 \%$ methanol

253 and analysed by the HPLC assay described above.

254

255 2.5. Micellar size

256

Analysis of micelle size distribution of the copolymer solutions before and after

258 crosslinking was conducted using dynamic light scattering (Zetasizer Nano, Malvern Instruments,

259 UK). The polymer solutions (1\% w/v) were prepared in phosphate buffer $(0.067 \mathrm{M}, \mathrm{pH} 7.4)$ and

260 clarified by filtering through a PVDF filter (Millipore, $0.45 \mu \mathrm{m}$ pore size) into a clean scattering

261 cell.

262

\section{2.6. Drug solubilisation}

The solubilisation method has been reported previously (Crothers et al., 2005). Briefly,

266 saturated drug-loaded solutions were prepared by suspending excess griseofulvin in $5 \mathrm{ml}$ of $1 \%$

267 w/v copolymer solutions and stirring at $37{ }^{\circ} \mathrm{C}$ for three days. The unsolubilised drug was then

268 filtered (Millipore, $0.45 \mu \mathrm{m}$ ). The amount of drug solubilised was determined by UV assay. The 
269 filtrate was diluted 10 times with methanol, and the UV absorbance was determined at optimum

270 wavelength $292 \mathrm{~nm}$ (Jenway 7315 spectrophotometer). The absorbance of the polymers at the

271 same dilution was also measured and deducted from the result. Calibration with drug alone

272 provided satisfactory Beer's law plots. All measurements were carried out in triplicate and the 273 results averaged.

274

275 2.7. Drug release study

276

277

278 Aliquots of $100 \mu 1$ saturated drug-loaded copolymer solutions (1\% w/v) were placed into 10

279 Slide-A-Lyzer ${ }^{\circledR}$ MINI Dialysis units. The dialysis was performed under sink conditions against

280 buffer solutions in a stirring water bath at $37{ }^{\circ} \mathrm{C}$ for $24 \mathrm{~h}$. A dialysis unit was taken out at specific

281 time interval. The solution was diluted with methanol and the amount of griseofulvin remained

282 in the unit were measured by the UV assay described above. All measurements were carried out

283 in triplicate and the results averaged. Statistical analysis of the data was carried out using the

284 Student's t-test. Probability values of $p<0.05$ were considered to be statistically significant. 285

$286 \quad 3 . \quad$ Results and discussion

288 3.1. Synthesis and Characterisation of MPEG-poly(ester-sulfide) copolymers 
As shown in Scheme 1, a series of linear-dendritic copolymers of MPEG and poly(ester-

291 sulfide) dendron were synthesised by stepwise reactions of acrylation and thiol-ene

292 photochemical reaction. Acrylation with acryloyl chloride is efficient to introduce acrylic groups

293 and excess acryloyl chloride was easily removed by evaporation and precipitation. Thiol-ene

294 reaction was classified as a click reaction, which can be performed under mild reaction

295 conditions and has a very high yield. Structures up to generation 2.5 poly(ester-sulfide) dendron

296 was constructed on the hydroxyl end of a linear MPEG by this scheme.

297 The complete conversion of dendritic surface function at each reaction step was confirmed

298 by ${ }^{1} \mathrm{H}$ and ${ }^{13} \mathrm{C}$ NMR, which indicates the successful formation of the dendritic structure.

299 Representative ${ }^{1} \mathrm{H}$ and ${ }^{13} \mathrm{C}$ NMR spectra of MEPG-DEN copolymers (full generation G2 and half

300 generation G2.5) are shown in Fig. 1. Acrylation of MPEG results in the peaks of two methylene

301 groups next to the hydroxyl end to shift from $72.3 \mathrm{ppm}$ to $69.1 \mathrm{ppm}$ and from $61.3 \mathrm{ppm}$ to 63.6

302 ppm in ${ }^{13} \mathrm{C}$ NMR spectrum, respectively. Three peaks from the acrylic group appear at 128 and

$303131 \mathrm{ppm}$ for ethenyl group and $166 \mathrm{ppm}$ for carbonyl group. The acrylic group undergoes free

304 radical addition with thiol group in thiol-ene reaction to form hydroxyl-functioned dendrons.

305 Then the two ethenyl peaks downshifted to 27.4 and 34.7 ppm while the carbonyl peak upshifted

306 to $171.8 \mathrm{ppm}$. Two new peaks located at 35.5 and $65.3 \mathrm{ppm}$ are from the methylene groups of

307 thioglycerol. The $\mathrm{CH}$ peak of thioglycerol is overlapped with the big peak of MPEG backbone.

308 Further acrylation of hydroxyl-terminated dendrons results in the two methylenes of thioglycerol

309 to downshift from 35.5 and 65.3 to 32.2 and $63.6 \mathrm{ppm}$ in ${ }^{13} \mathrm{C} \mathrm{NMR}$, respectively. The acrylic

310 groups showed multiple peaks at 128,131 and $165 \mathrm{ppm}$ due to the slightly different chemical

311 environment when attaching on primary or secondary hydroxyl groups. In ${ }^{1} \mathrm{H} \mathrm{NMR}$, a group of

312 well-separated peaks are shown between 5.8 and $6.5 \mathrm{ppm}$ after acrylation, which are from the 
313 protons of the ethenyl groups. After addition with thiol groups, those peaks are completely

314 removed, indicative of the full conversion of acrylic groups to hydroxyl functional groups.

315 The MPEG-DEN-G2.5 copolymer was characterised by GPC to determine the molecular

316 weight. As shown in the chromatogram (Fig. 2), the retention time of MPEG-DEN-G2.5 is lower

317 than that of free MPEG, which indicates an increase in the molecular weight. The molecular

318 weight obtained via calibration is $5510 \mathrm{~g} \mathrm{~mol}^{-1}$, which is smaller than the value calculated from

319 NMR (5702 $\left.\mathrm{g} \mathrm{mol}^{-1}\right)$. This discrepancy is thought to be due to the more compact dendritic

320 structure and thus smaller size compared to linear polymers with a similar molecular weight.

\subsection{Critical Micelle Concentration}

The half generation MPEG-DEN copolymers, comprising a hydrophilic PEG chain and a

325 hydrophobic dendron with ethenyl surface groups, are able to micellise in aqueous solution. The

326 drop-shape analysis method was employed to determine the CMCs of the copolymers. The

327 method is sensitive to measure the surface tension at low concentrations and only requires small

328 quantities of sample (Zhou et al., 2013). However, the measurements were performed at room

329 temperature (approx. $20^{\circ} \mathrm{C}$ ) due to lack of temperature control accessories.

330 The CMC of the MPEG-DEN-G2.5 copolymer determined from inflection points in plots

331 of surface tension versus logarithm concentration (Fig. 3) was $0.9 \mathrm{~g} \mathrm{dm}^{-3}$. Fury et al. reported the

332 CMC measurement of MPEG-poly(ester-sulfide) copolymer (synthesised using pentenoyl

333 chloride) (Fury et al., 2013). A lower CMC value $\left(7.5 \mathrm{mg} \mathrm{dm}^{-3}\right)$ was found for the $\mathrm{G} 3.5$

334 copolymer with 8 ethenyl groups. This is probably due to the longer alkenyl building units and

335 doubled hydrophobic surface groups. In this paper the micellar properties and solubilisation 
336 characteristics of the copolymers were measured in $1 \% \mathrm{w} / \mathrm{v}\left(10 \mathrm{~g} \mathrm{dm}^{-3}\right)$ aqueous solution. It was

337 assumed that micellisation is complete at the concentration and temperature. The surface tension 338 measurement of full generation MPEG-DEN copolymers showed that no CMC was detected at

339 the equivalent concentration range. It indicates that full generation MPEG-DEN copolymers are 340 not able to form micelles due to the hydrophilicity of their hydroxyl surface groups. This is in 341 agreement with the findings reported by Fury et al. (Fury et al, 2013).

\subsection{Preparation of core-crosslinked micelles}

As shown in Fig. 4, half generation MPEG-DEN copolymers are amphiphiles that can selfassociate in dilute aqueous solutions. Hydrophobic poly(ester-sulfide) dendrons form the micelle cores while hydrophilic MPEG chains form the periphery of the micelles. The G2.5 Poly(ester sulphide) dendron has 4 ethenyl surface groups that are suitable for crosslinking via reaction with

349 an appropriate linker. The bithiol linker DTT and photoinitiator Irgacure 2959 were added into a

350 pre-prepared micellar solution of MPEG-DEN-G2.5. DTT and Irgacure 2959 are soluble in a 351 wide range of aqueous and organic solvents. They can be easily dispersed in water and then 352 penetrate into the micelle cores. Thiol-ene photoreaction was initiated by UV radiation and 353 excess DTT was removed by dialysis after crosslinking. The completion of crosslinking was 354 confirmed by ${ }^{1} \mathrm{H}$ NMR. The peaks from the ethenyl groups (5.8-6.5 ppm) disappeared after 355 reaction, which indicates full conversion of the ethenyl groups.

356 The formation of the core-crosslinked micelles was confirmed by HPLC equipped with a 357 CAD detector. Charged aerosol detection (CAD) has been introduced as a powerful technique in 358 combination with HPLC to analyse compounds without strong UV chromophores (Vehovec and 
359 Obreza, 2010; Almeling et al., 2012). The HPLC eluent is nebulised with a flow of nitrogen to

360 form droplets. The volatile components and mobile phase are then evaporated to obtain analyte

361 particles. The particles are charged by meeting with a secondary stream that has passed a high-

362 voltage platinum wire. The resulting positively-charged particles are collected and measured by

363 an electrometer. CAD detector is mass-dependent and the response is generated regardless of the

364 spectral and physicochemical properties of analytes.

Fig. 5 shows the CAD chromatogram of MPEG, non-crosslinked and crosslinked micelles of MPEG-DEN-G2.5 copolymers. The polymers were analysed by reversed-phase HPLC and

367 separated by the hydrophobic interaction with the stationary phase of the C18 column. MPEG

368 are hydrophilic molecules and eluted fast from the column. MPEG shows a narrow peak due to

369 its low polydispersity and the similar polarity of all the molecules. However the hydrophobic

370 poly(ester-sulfide) dendrons, especially the ethenyl groups, can interact with the stationary phase,

371 which increases the retention time of the linear-dendritic copolymers. The micelles of MPEG-

372 DEN-G2.5 copolymer are unstable upon dilution in mobile phase and could disassociate fully or

373 partially during elution in the column. The molecules of MPEG-DEN-G2.5 copolymer exhibit

374 various polarities as the hydrophobic dendrons are conjugated to MPEG molecules with different

375 chain lengths. Hence the MPEG-DEN-G2.5 copolymer was eluted more slowly and separated

376 into fractions. This explains the multiple broad peaks seen in the chromatogram. Compared to

377 the non-crosslinked micelles, the core-crosslinked MPEG-DEN micelles only show a single peak

378 which is very similar to MPEG but relatively broader. The micelles are stable after crosslinking

379 and remain intact during elution. The crosslinked micelles have a relatively uniform structure

380 and the hydrophobic micelle cores are shielded by the MPEG corona. So they demonstrate

381 similar polarity and thus retention time to MPEG. 


\section{3.4. Stability of core-crosslinked micelles} copolymer was investigated in acidic and neutral solutions. As shown in Fig. 6, both the

387 crosslinked and non-crosslinked micelles have good stability at $\mathrm{pH}$ 7.4. No degradation was 388 detected for the crosslinked micelles after 2 days. The peaks of the non-crosslinked micelles 389 were reduced slightly due to the dynamic equilibrium of micellisation and relatively direct 390 exposure of the molecules to the solvent. The MPEG-DEN copolymers contain ester bonds and 391 thus more readily hydrolyse in acidic solutions. The dendritic branches could be fully or partially

392 cleaved from the MPEG chains, which results in an increase of the polarity and a decrease of the 393 retention time. Fig. 7 showed that both micelles demonstrated more apparent changes after 394 incubation at $\mathrm{pH} 1.2$ for $24 \mathrm{~h}$. The peak at $2.1 \mathrm{~min}$ is from the chloride ions in the buffer. The 395 non-crosslinked micelles showed clear sign of degradation over the elution range. The peaks of 396 the more hydrophobic fractions were greatly reduced and the copolymers were eluted faster due 397 to the increased hydrophilicity. The crosslinked micelles also showed a similar tendency. The 398 peaks became more narrow and the retention times were slightly decreased. Although the 399 evidence of hydrolysis was found by the CAD technique, the quantitative determination of the 400 degradation of the copolymers is not achievable due to lack of calibration standards. As CAD 401 detection is mass-dependent not concentration-dependent, different compounds could be eluted 402 at the same time and produce very close responsive signals in the detector. However the CAD 403 cannot provide any spectral information to identify the compounds. The results of the stability 404 study indicate that the copolymers are relatively stable under neutral conditions. Crosslinking 
405 within the micelle cores could enhance the stability of micelles, limit the access to the

406 surrounding solutions and retard the hydrolysis of the copolymers.

407

408 3.5. Micellar size

409

The MPEG-DEN copolymers are nonionic polymeric surfactants and hence $\mathrm{pH}$ will not

411 have an impact on their micellar properties. The micellar properties of the MPEG-DEN

412 copolymers were measured in aqueous phosphate buffer (0.067 M, pH7.4) to assure the stability

413 of the copolymers during the measurement. The effect of the buffer on the micellar properties is

414 negligible because of its low ionic strength. Dynamic light scattering was used to measure the

415 micellar size of the polymers in dilute aqueous solutions. It was found that the hydrodynamic

416 radius of MPEG molecules in $1 \% \mathrm{w} / \mathrm{v}$ buffer solution at $25^{\circ} \mathrm{C}$ is approx. $2.5 \mathrm{~nm}$ (Fig. 8). In

417 contrast, the size distribution curve for $1 \% \mathrm{w} / \mathrm{v}$ micellar solution of the MPEG-DEN-G2.5

418 copolymer showed a peak at ca. $12.5 \mathrm{~nm}$ (radius) taken as evidence of association to form

419 spherical micelles. The size distribution is within the similar range (diameter 10 100 nm) of the

420 MPEG-G3.5 poly(ester-sulfide) copolymer reported by Fury et al. 2013, which shows a larger

421 peak size at $\mathrm{r} \approx 20 \mathrm{~nm}$ due to the larger dendrons with longer alkenyl building units. The core-

422 crosslinked MPEG-DEN-G2.5 micelles show a very similar size distribution to the non-

423 crosslinked micelles under the equivalent conditions, which indicates that the crosslinking within

424 the micelle cores does not affect the micelle size.

425

\subsection{Drug solubilisation}


The amphiphilic MPEG-DEN copolymers can self-associate to form micelles with a

429 dendritic micelle core and hydrophilic MPEG corona. The hydrophobic cores are the favoured

430 domain for encapsulation of poorly water-soluble drugs. Compared to linear molecules the core-

431 forming dendritic blocks are not able to closely packed due to steric hindrance and thus could

432 lead to a relatively large core size. The MPEG corona is also a possible site for incorporation of

433 guest molecules. Crothers et al. investigated the solubilisation of griseofulvin in solutions of

434 PEG6000 in excess of the solubility in water (Crothers et al., 2005). The solubilisation capacity

435 of $2 \mathrm{mg}$ of griseofulvin per gram of polymer was obtained for a $10 \mathrm{wt} \% \mathrm{PEG}$ solution. The

436 solubilisation of griseofulvin showed a linear increase with the concentration of PEG6000 in

437 solutions. In this work the solubilisation of MPEG-DEN copolymers was measured in $1 \% \mathrm{w} / \mathrm{v}$

438 solution. The mass fraction of MPEG5000 in the copolymers is less than 0.87 . Thus the volume

439 of PEG micelle corona in solution is rather small. So the contribution of MPEG corona to the

440 solubilisation capacities of the copolymers is negligible.

441 Table 1 shows the solubility of griseofulvin in the buffer solutions of the crosslinked and

442 non-crosslinked MPEG-DEN micelles at $37^{\circ} \mathrm{C}$. An approx. 10-fold increase of the solubility was

443 found for both copolymer solutions at $1 \% \mathrm{w} / \mathrm{v}$. The solubility of griseofulvin in phosphate buffer

$444\left(0.01 \mathrm{mg} \mathrm{ml}^{-1}\right)$ was deducted for calculation of the solubilisation capacity $\left(\mathrm{S}_{\mathrm{cp}}\right.$, expressed as

445 milligram drug per gram of copolymer). The crosslinked micelles show relatively higher

446 solubilisation capacity than the non-crosslinked ones under equivalent conditions. The micelle

447 size measurement indicates that both micelles have very similar hydrodynamic radii and

448 crosslinking has no impact on the size of micelle cores. It is known that micellisation is a

449 thermodynamic equilibrium and thus the drug molecules encapsulated are possible to diffuse out

450 of the micelle cores. However the escape of drug molecules is considered to be hindered by core- 
451 crosslinking that enhances the stability of the micelles. It should be noted that crosslinking can

452 also affect the diffusion of drug into the micelle. Therefore sufficient suspension time was

453 ensured in order to achieve saturated drug-loaded solutions. It was observed that an approximate

454 doubling of solubility of griseofulvin in the copolymer solutions was obtained by increasing

455 solution concentration from 1 to $2 \% \mathrm{w} / \mathrm{v}$. The micellisation was considered to be completed

456 under the measurement conditions due to the low CMC of the copolymers. Hence an increase of

457 concentration was expected to increase the number of micelles. Although the solubility increases

458 the concentration, the solubilisation capacities of the copolymers remain the same as the

459 concentration does not affect the micelle size and thus the number of drug molecules

460 incorporated in each micelle.

461

\section{$462 \quad$ 3.7. Drug release profiles}

463 The stability study indicates that the MPEG-DEN copolymers have good stability under 464 neutral conditions. Hence the main mechanism of drug release at $\mathrm{pH} 7.4$ is attributed to the 465 diffusion of molecules out of the micelles. Fig. 9 shows the release profiles of griseofulvin from $4661 \% \mathrm{w} / \mathrm{v}$ buffer solution $(\mathrm{pH} 7.4)$ of crosslinked and non-crosslinked MPEG-DEN-G2.5

467 copolymers at $37^{\circ} \mathrm{C}$. The sink condition was ensured by refreshing phosphate buffer during 468 dialysis. A rapid release with approximately $36 \%$ and $57 \%$ drug within the initial $6 \mathrm{~h}$ was seen 469 for crosslinked and non-crosslinked copolymer solutions, respectively. The release curves 470 showed that approximately $60 \%$ and $85 \%$ griseofulvin was released from the copolymer 471 solutions after $24 \mathrm{~h}$ of dialysis where a plateau was reached. Drug release from the crosslinked 472 micelles was significantly $(\mathrm{p}<0.05)$ more sustained than from the non-crosslinked micelles, 473 attributable to the crosslinking structure within the micelle cores which may hinder the diffusion 
474 of drug molecules. To investigate the effect of hydrolysis of copolymers on the drug release, the

475 release of griseofulvin from $1 \% \mathrm{w} / \mathrm{v}$ crosslinked micellar solution at $\mathrm{pH} 1.2$ was also measured

476 (Fig. 9). A slightly faster release rate was observed under acidic conditions at the initial stage of

477 dialysis and a significant $(\mathrm{p}<0.05)$ increase of the amount of drug released (approximately 15\%)

478 was found after $24 \mathrm{~h}$. The acceleration of release is due to the degradation of hyperbranched

479 micelle cores or cleavage of the MPEG chains from the micelle corona.

\section{4. Conclusions}

484 a combination of acrylation and thiol-ene photochemical reaction. The surface functionality of

485 dendrons was found to have an impact on the physicochemical properties of the linear-dendritic 486 copolymers, especially their micellisation behavior in aqueous solutions. The half generation 487 MPEG-DEN copolymers with ethenyl groups are able to self-associate to form micelles with a 488 hydrophobic hyperbranched core and MPEG corona. Crosslinking within the micelle cores can 489 be initiated by UV radiation via thiol-ene reaction with dithiol linkers, which can reinforce the 490 micelle structure and enhance their stability. The copolymer micelles show good stability under 491 neutral conditions but readily hydrolyse in acidic solutions due to the cleavage of ester bonds in 492 the dendrons. The micelles of the copolymers demonstrated the capability to increase the 493 solubility of poorly water-soluble drugs by incorporation of the drug in the hydrophobic cores.

494 The release profiles from the copolymer solutions indicated that crosslinked micelles showed 495 more sustained release of griseofulvin than the non-crosslinked micelles attributable to the 
496 improved stability and crosslinked core structure. This study explores a new strategy on

497 designing biodegradable crosslinked micelles for drug solubilisation and delivery.

498

499 Acknowledgements

The authors would like to thank Dr Zhuo Yang for assistance with copolymer

501 characterisation. This work was financially supported by the University of Central Lancashire

502 under a science research program.

504 References

505

506 Adams, M.L., Lavasanifar, A., Kwon, G.S., 2003. Amphiphilic block copolymers for drug delivery. J. Pharm. Sci. 92, 1343-1355.

508 Almeling, S., Ilko, D., Holzgrabe, U., 2012. Charged aerosol detection in pharmaceutical 509 analysis. J. Pharm. Biomed. Anal. 69, 50-63.

510 Attwood, D., Zhou, Z., Booth, C., 2007. Poly(ethylene oxide) based copolymers: solubilisation 511 capacity and gelation. Expert Opin. Drug Deliv. 4, 533-546.

512 Chen, W., Meng, F., Cheng, R., Deng, C., Feijen, J., Zhong, Z., 2015. Facile construction of 513 dual-bioresponsive biodegradable micelles with superior extracellular stability and 514 activated intracellular drug release. J. Control. Rel. 210, 125-133.

515 Crothers M., Zhou Z., N. Ricardo M.P.S., Yang Z., Taboada P., Chaibundit C., Attwood D., 516 Booth C., 2005. Solubilisation in aqueous micellar solutions of block copoly(oxyalkylene)s.

517 Int. J. Pharm., 293, 91-100. 
518 D'Emanuele, A., Attwood, D., 2005. Dendrimer-drug interactions. Adv. Drug. Deliv. Rev. 57, 519 2147-2162.

520 D’Emanuele, A., Zhou, Z., Attwood, D., Abu-Rmaileh, R. Dendrimers. In: Swarbrick, J. (Ed.), 521 Encyclopaedia of Pharmaceutical Science and Technology. Fourth ed. 2013. CRC press, 522 Taylor and Francis: New York, pp. 799-818.

523 Esfand, R., Tomalia, D.A., 2001. Poly(amidoamine) (PAMAM) dendrimers: from biomimicry to 524 drug delivery and biomedical applications. Drug Disc. Today 6, 427-436.

525 Fury, J. J., Altenhofer, E.F., Sedaghat-Herati, R., 2009. Synthesis of new poly(ethylene glycol)526 block-poly(ester sulfide) dendrimers. Tetrahedron Lett. 50, 4205-4207.

527 Fury, J.J., Robison, J., Sedaghat-Herati, R., 2013. Synthesis and self-assembly of new 528 poly(ethylene glycol)-block-poly(ester-sulfide) dendrimers. J. Macromol. Sci., Pure Appl. $529 \quad$ Chem. 50, 1113-1120.

530 Gauchera, G., Satturwara, P., Jonesa, M., Furtosb, A., Leroux, J.C., 2010. Polymeric micelles for 531 oral drug delivery. Eur. J. Pharm. Biopharm. 76, 147-158.

532 Gitsov, I., Fréchet, J. M. J., 1993. Solution and solid-state properties of hybrid linear-dendritic 533 block copolymers. Macromolecules 26, 6536-6546.

534 Hu, X., Chen, X., Wei, J., Liu, S., Jing, X., 2009. Core crosslinking of biodegradable block 535 copolymer micelles based on poly(ester carbonate). Macromol. Biosci. 9, 456-463.

536 Huang, Y., Sun, R., Luo, Q., Wang, Y., Zhang, K., Deng, X., Zhu W., Li, X., Shen, Z., 2016. In 537 situ fabrication of paclitaxel-loaded core-crosslinked micelles via thiol-ene "click" 538 chemistry for reduction-responsive drug release. J. Polym. Sci. A Polym. Chem. 54, 99539107. 
540 Killops, K.L., Campos, L.M., Hawker, C.J., 2008. Robust, efficient, and orthogonal synthesis of 541 dendrimers via thiol-ene "click" chemistry. J. Am. Chem. Soc. 130, 5062-5064.

542 Kim, J.S., Youk, J.H., 2009. Preparation of core cross-linked micelles using a photo-cross$543 \quad$ linking agent. Polymer 50, 2204-2208.

544 Kwon, G.S., 2003. Polymeric micelles for delivery of poorly water-soluble compounds. Crit. $545 \quad$ Rev. Ther. Drug Carrier Syst. 20, 357-403.

546 Li, Y., Shen, Y., Wang, S., Zhu, D., Du, B., Jiang, J., 2015. Disulfide cross-linked cholic-acid modified PEG-poly(amino acid) block copolymer micelles for controlled drug delivery of doxorubicin. RSC Adv. 5, 30380-30388.

Li, Y., Xiao, K., Luo, J., Xiao, W., Lee, J.S., Gonik, A.M., Kato, J., Dong, T.A., Lam, K.S., 2011.

550 Well-defined, reversible disulfide cross-linked micelles for on-demand paclitaxel delivery. $551 \quad$ Biomaterials 32, 6633-6645.

552 Liu, S., Weaver, J.V.M., Save, M., Armes, S.P., 2002. Synthesis of pH-responsive shell cross553 linked micelles and their use as nanoreactors for the preparation of gold nanoparticles. $554 \quad$ Langmuir $18,8350-8357$.

555 Van Nostrum, C.F., 2011. Covalently cross-linked amphiphilic block copolymer micelles. Soft $556 \quad$ Matter 7, 3246-3259.

557 O’Reilly, R.K., Hawker, C.J., Wooley, K.L., 2006. Cross-linked block copolymer micelles: 558 functional nanostructures of great potential and versatility. Chem. Soc. Rev. 35, 1068-1083. 559 Quan, C., Wei, H., Shi, Y., Li, Z., Cheng, S., Zhang, X., Zhuo, R., 2011. Fabrication of 560 multifunctional shell cross-linked micelles for targeting drug release. Colloid Polym Sci. $561 \quad 289,667-675$. 
562 Read, E.S., Armes, S.P., 2007. Recent advances in shell cross-linked micelles. Chem. Commun. $563 \quad 3021-3035$.

564 Torchilin, V. P., 2001. Structure and design of polymeric surfactant-based drug delivery systems. $565 \quad$ J. Control. Rel. 73, 137-172.

566 Vehovec, T., Obreza, A., 2010. Review of operating principle and applications of the charged 567 aerosol detector. J. Chromatogr. A 1217, 1549-1556.

568 Williams, H. D., Trevaskis, N. L., Charman, S. A., Shanker, R. M., Charman, W. N., Pouton, C. 569 W., Porter, C. J. H., 2013. Strategies to address low drug solubility in discovery and 570 development. Pharmacol. Rev. 65, 315-499.

571 Whitton, G., Gillies, E.R., 2015. Functional aqueous assemblies of linear-dendron hybrids. J. 572 Polym. Sci. A Polym. Chem. 53, 148-172.

573 Wu, Y., Chen, W., Meng, F., Wang, Z., Cheng, R., Deng, C., Liu, H., Zhong, Z, 2012. Core$574 \quad$ crosslinked $\mathrm{pH}$-sensitive degradable micelles: A promising approach to resolve the 575 extracellular stability versus intracellular drug release dilemma. J. Control. Rel. 164, 338$576 \quad 345$.

577 Xiong, J., Meng, F., Wang C., Cheng, R., Liu, Z., Zhong, Z., 2011. Folate-conjugated 578 crosslinked biodegradable micelles for receptor-mediated delivery of paclitaxel. J. Mater. $579 \quad$ Chem. 21, 5786-5794.

580 Yue, J., Wang, R., Liu, S., Wu, S., Xie, Z., Huang, Y., Jing, X., 2012. Reduction-responsive 581 shell-crosslinked micelles prepared from Y-shaped amphiphilic block copolymers as a drug $582 \quad$ carrier. Soft Matter 8, 7426-7435. 
583 Zhang, Y., Xiao, C., Li, M., Ding, J., He, C., Zhuang, X., Chen, X., 2014. Core-cross-linked

584 micellar nanoparticles from a linear-dendritic prodrug for dual-responsive drug delivery.

$585 \quad$ Polym. Chem. 5, 2801-2808.

586 Zhou, Z., D’Emanuele, A., Attwood, D., 2013. Solubility enhancement of paclitaxel using a 587 linear-dendritic block copolymer. Int. J. Pharm. 452, 173-179.

588 Zhou, Z., D'Emanuele, A., Lennon, K., Attwood, D., 2009. Synthesis and micellization of linear589 dendritic copolymers and their solubilization ability for poorly water-soluble drugs.

$590 \quad$ Macromolecules 42, 7936-7944.

591

592 Figure legends

593

594 Scheme 1. Synthesis of Methoxy-poly(ethylene glycol)-b-poly(ester-sulfide) dendron 595 copolymers.

599 Fig. $1 .{ }^{1} \mathrm{H}$ and ${ }^{13} \mathrm{C}$ NMR spectra of MPEG-DEN-G2.5 (1) and MPEG-DEN-G2 (2). The peaks at $600 \quad 52$ and $89 \mathrm{ppm}$ in ${ }^{13} \mathrm{C}$ NMR are the noise peaks generated by the instrument.

601

602 Fig. 2. GPC chromatogram of MPEG and MPEG-DEN-G2.5 copolymer.

603

604 Fig. 3. Surface tension versus logarithm concentration $\left(\mathrm{g} \mathrm{dm}^{-3}\right)$ for MPEG-DEN-G2.5 copolymer 605 at $20{ }^{\circ} \mathrm{C}$. 
607 Fig. 4. Schematic illustration of micellisation of half generation MPEG-DEN copolymers and 608 core-crosslinking of the micelles in the presence of DTT.

609

610 Fig. 5. HPLC chromatogram of MPEG, non-crosslinked and core-crosslinked micelles of 611 MPEG-DEN-G2.5 copolymer detected by CAD.

612

613 Fig. 6. HPLC chromatograms of non-crosslinked (a) and core-crosslinked micelles (b) of MPEG614 DEN-G2.5 copolymer at $\mathrm{pH} 7.4$ for $48 \mathrm{~h}$ detected by CAD.

616 Fig. 7. HPLC chromatograms of non-crosslinked (a) and core-crosslinked micelles (b) of MPEG617 DEN-G2.5 copolymer at $\mathrm{pH} 1.2$ for $24 \mathrm{~h}$ detected by CAD.

619 Fig. 8. Intensity fraction distributions of logarithm hydrodynamic diameter of MPEG ( $(\mathbf{\bullet})$ and 620 MPEG-DEN-G2.5 copolymer ( $\square$ ) in a $1 \%(\mathrm{w} / \mathrm{v})$ buffer solution at $37^{\circ} \mathrm{C}$.

622 Fig. 9. Drug release profiles from 1\% w/v micellar solutions of MPEG-DEN-G2.5 copolymer at $62337^{\circ} \mathrm{C}$ : non-crosslinked micelles at pH $7.4(\bullet)$, crosslinked micelles at pH $7.4(\bullet)$ and $\mathrm{pH} 1.2(\bullet)$ $624($ mean $\pm \mathrm{SD}, \mathrm{n}=3) .{ }^{*}$ indicates a significant difference $(\mathrm{p}<0.05)$ from crosslinked micelles at $\mathrm{pH}$ 6257.4. 


\begin{tabular}{lccc}
\hline MPEG-DEN-G2.5 & Conc. $/ \% \mathrm{w} / \mathrm{v}$ & $\mathrm{S} / \mathrm{mg} \mathrm{ml}^{-1}$ & $\mathrm{Scp} / \mathrm{mg} \mathrm{g}^{-1 \mathrm{a}}$ \\
\hline $\begin{array}{c}\text { Non-crosslinked } \\
\text { micelles }\end{array}$ & 1.0 & 0.101 & 9.1 \\
& 2.0 & 0.210 & 9.5 \\
Crosslinked micelles & 1.0 & 0.123 & 11.3 \\
& 2.0 & 0.242 & 11.1 \\
\hline
\end{tabular}

a. Measurement uncertainty $\pm 1 \mathrm{mg} \mathrm{g}^{-1}$. 


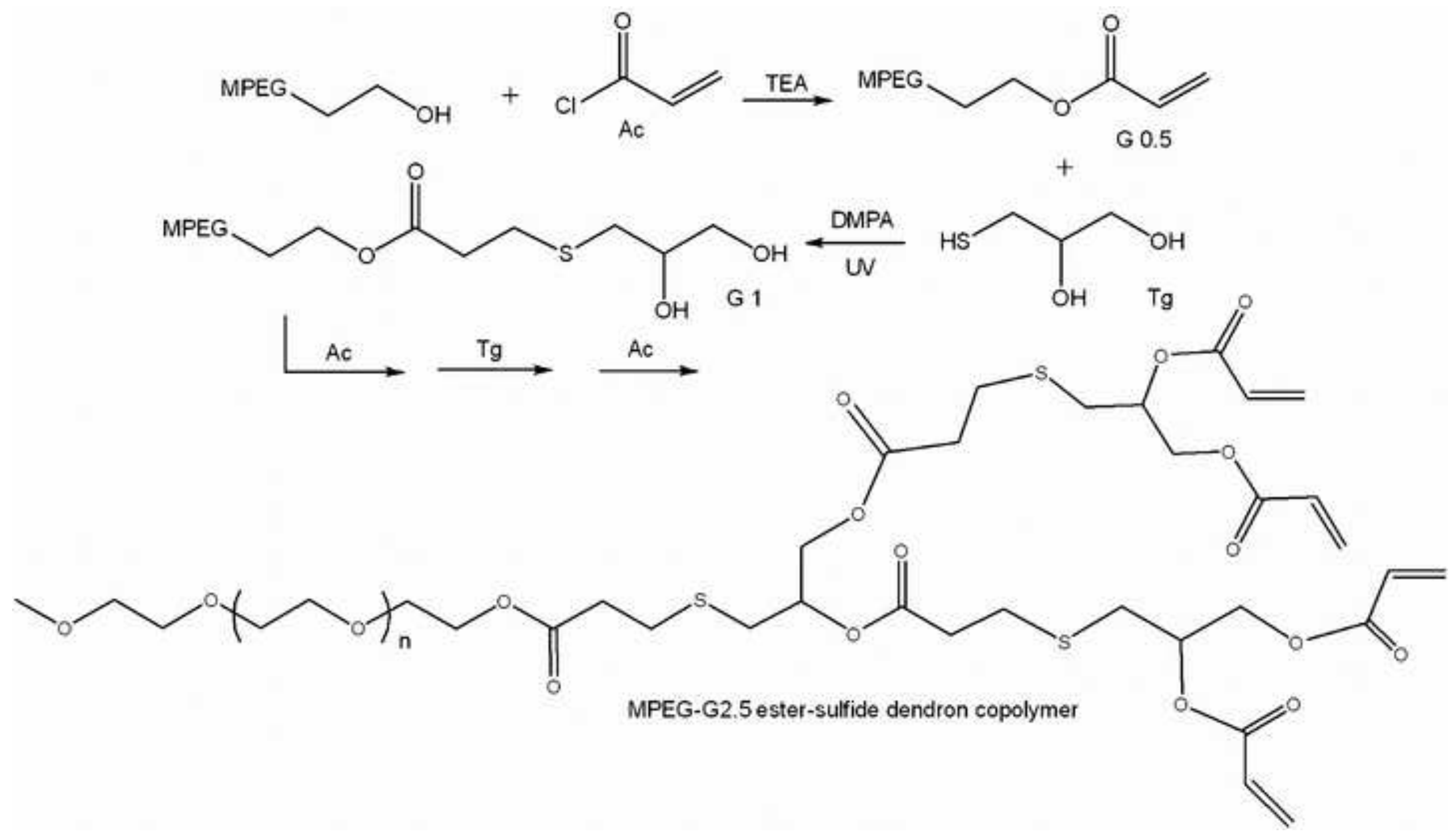




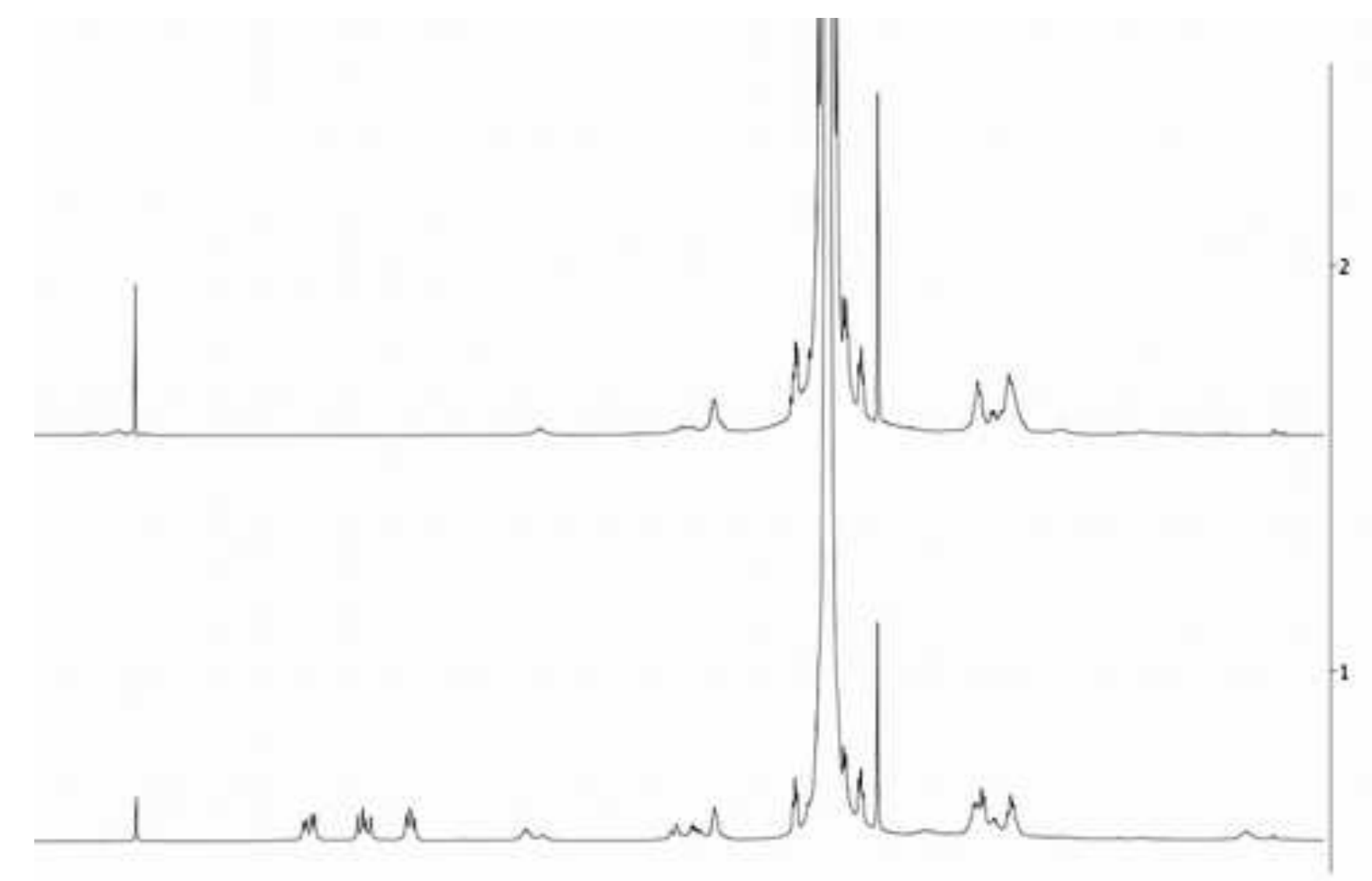

\begin{tabular}{|c|c|c|c|c|c|c|c|c|c|c|c|c|c|}
\hline 7.5 & 7.0 & 6.5 & 60 & 5.5 & 50 & $\begin{array}{c}4.5 \\
\mathrm{fi}(\mathrm{ppm})\end{array}$ & 4.0 & 3.5 & 3.0 & 2.5 & 2.0 & 1.5 & 1.0 \\
\hline
\end{tabular}
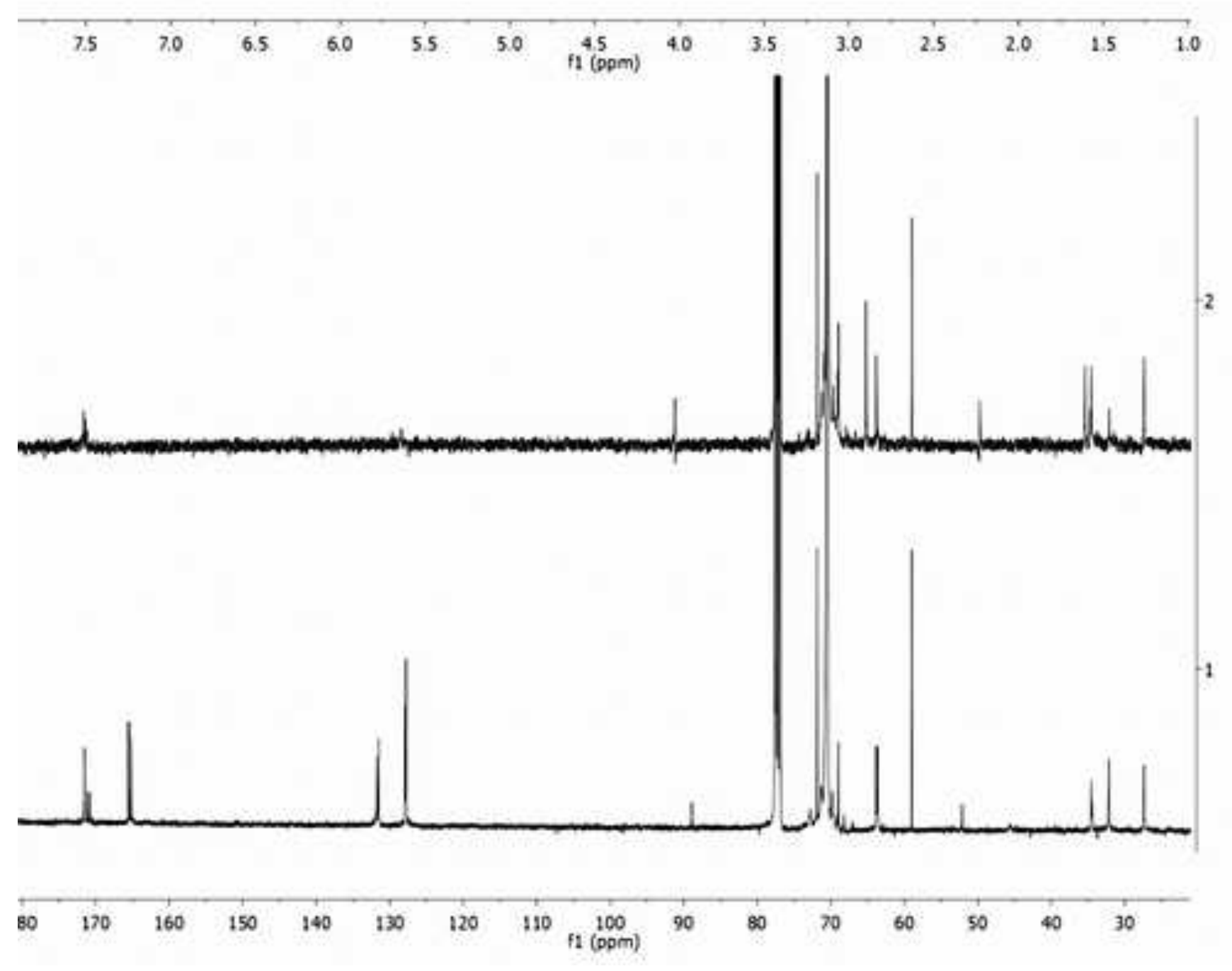

Figure 1 


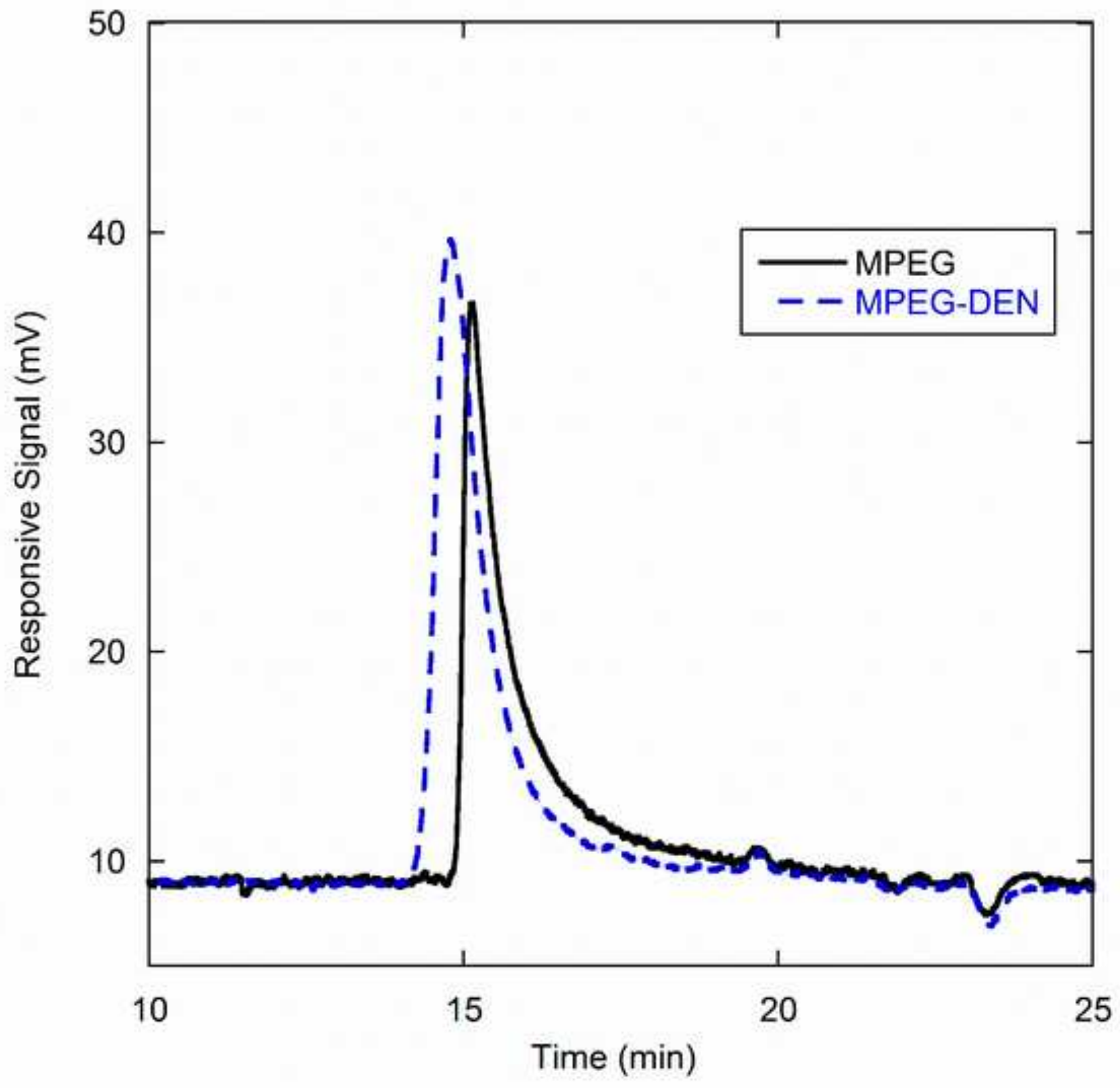




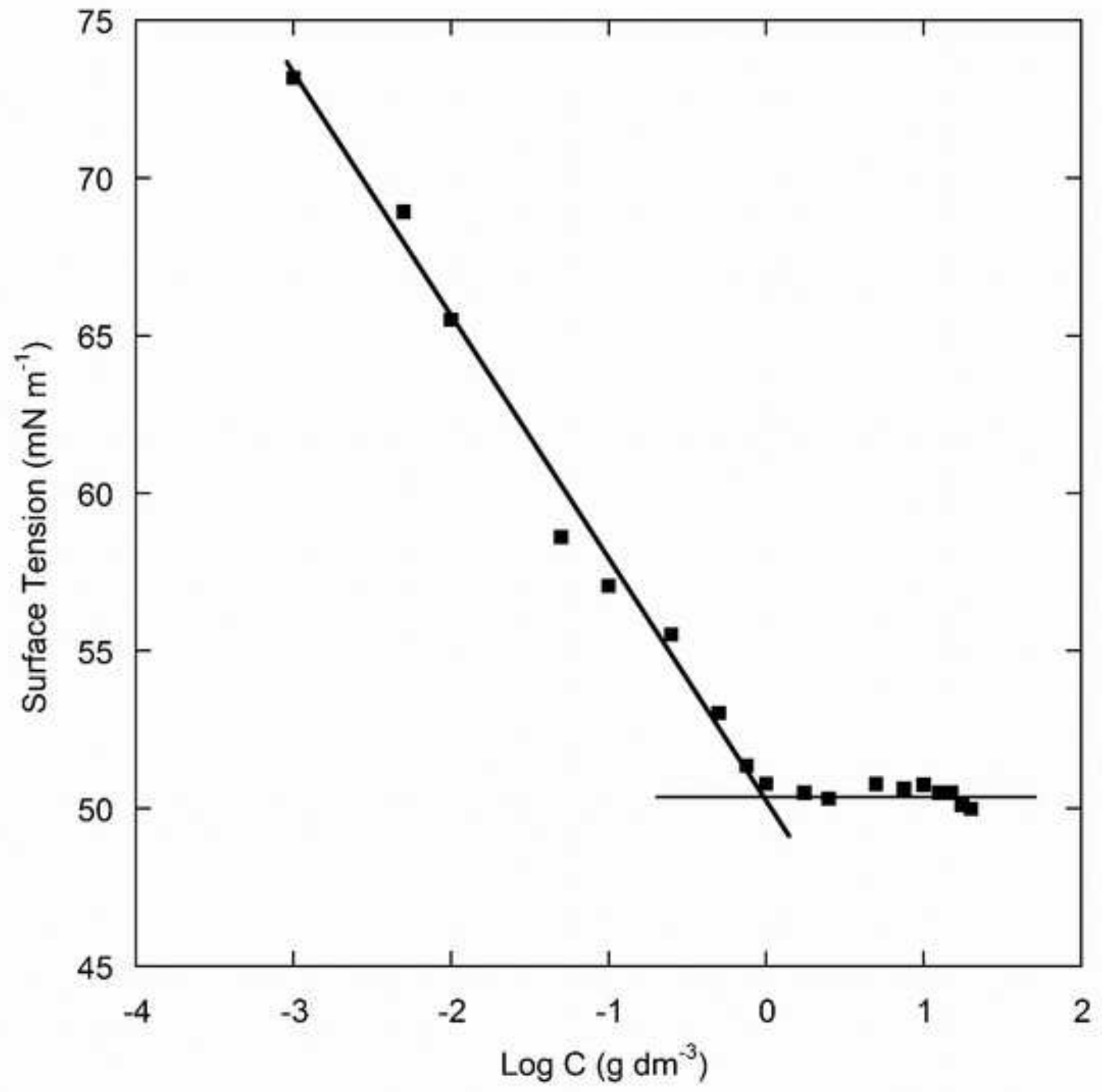




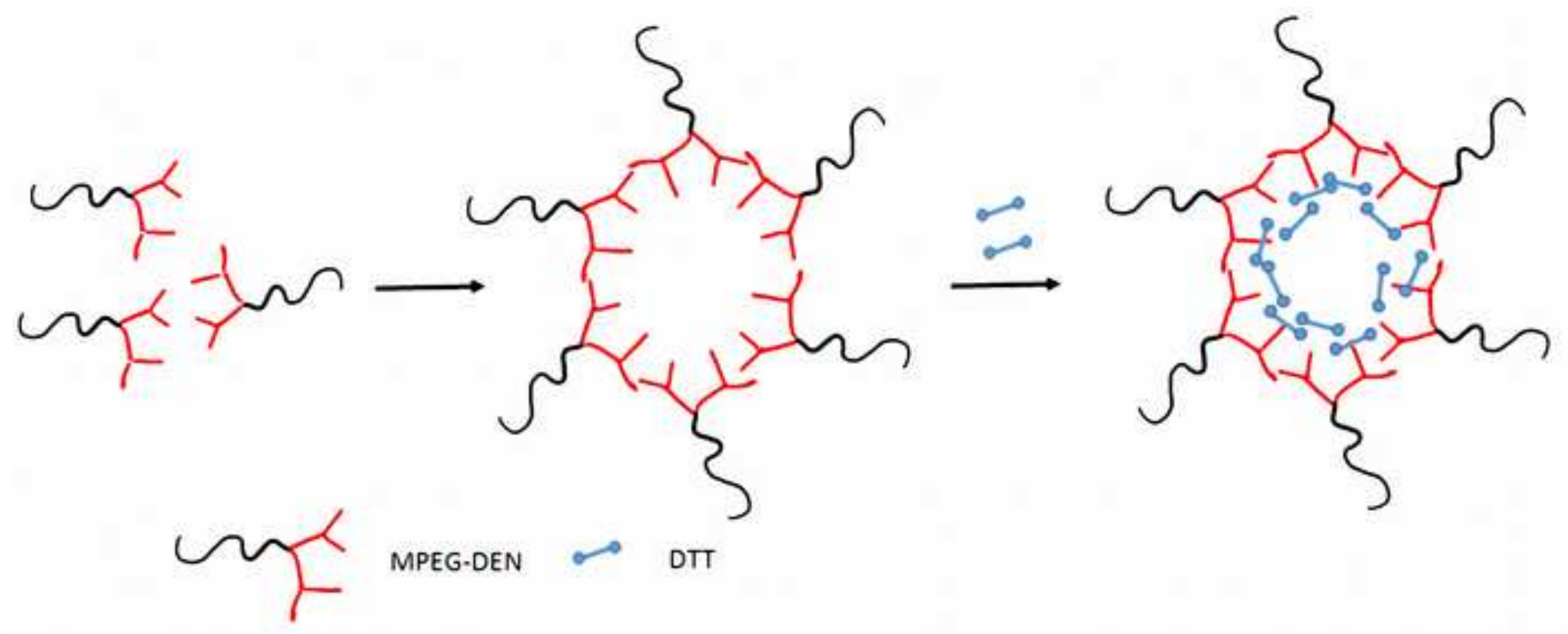




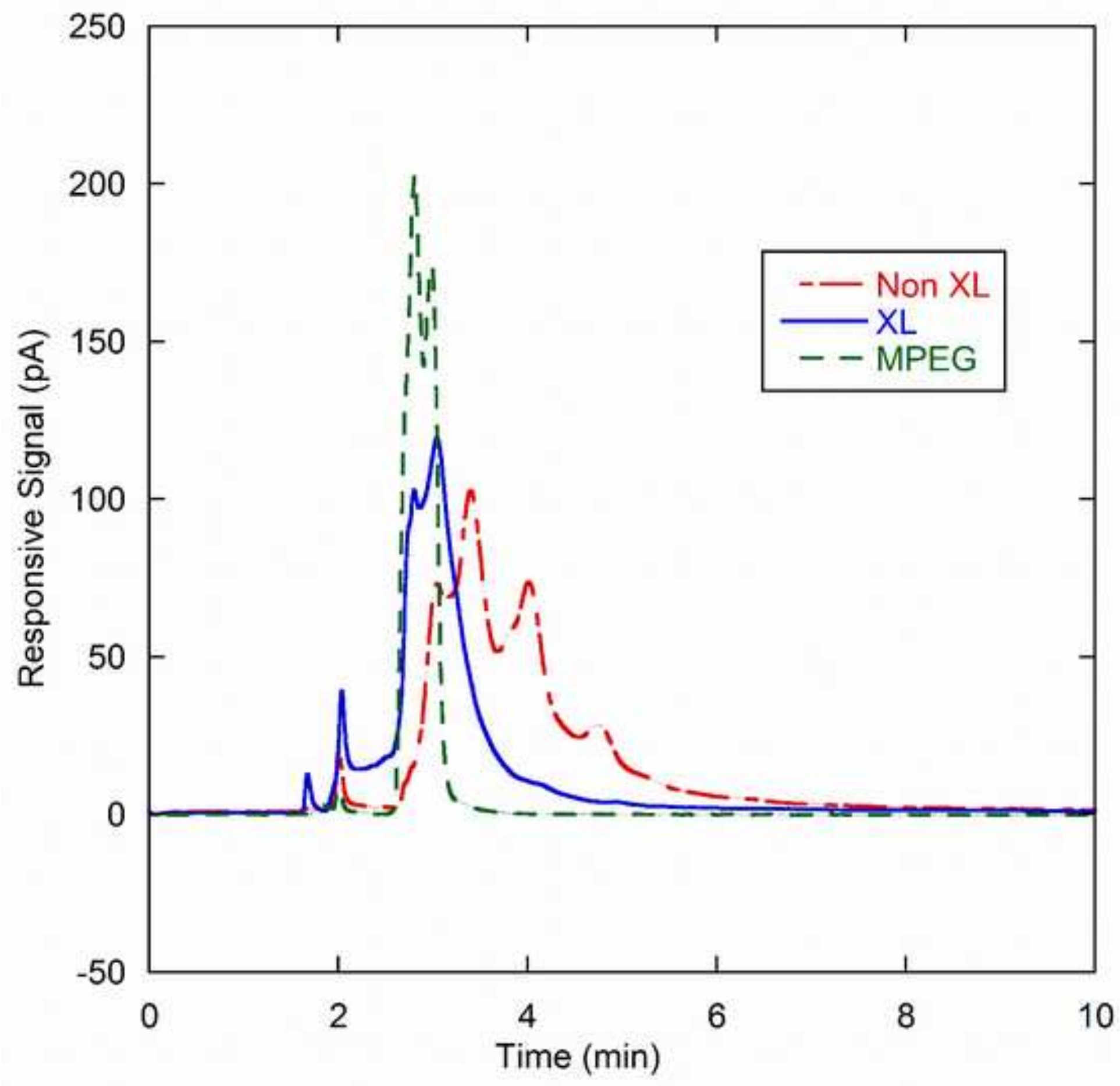



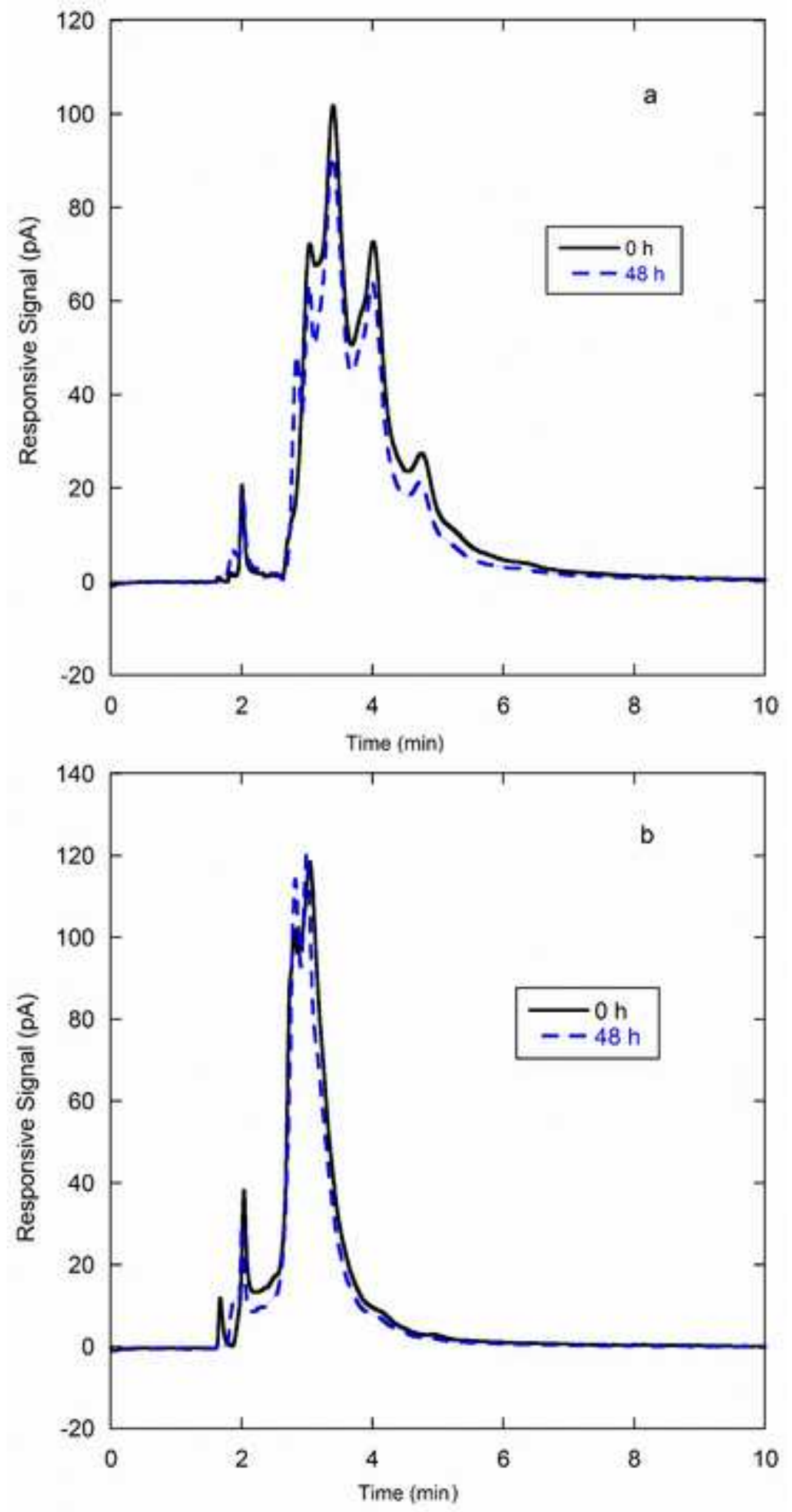

Figure 6 

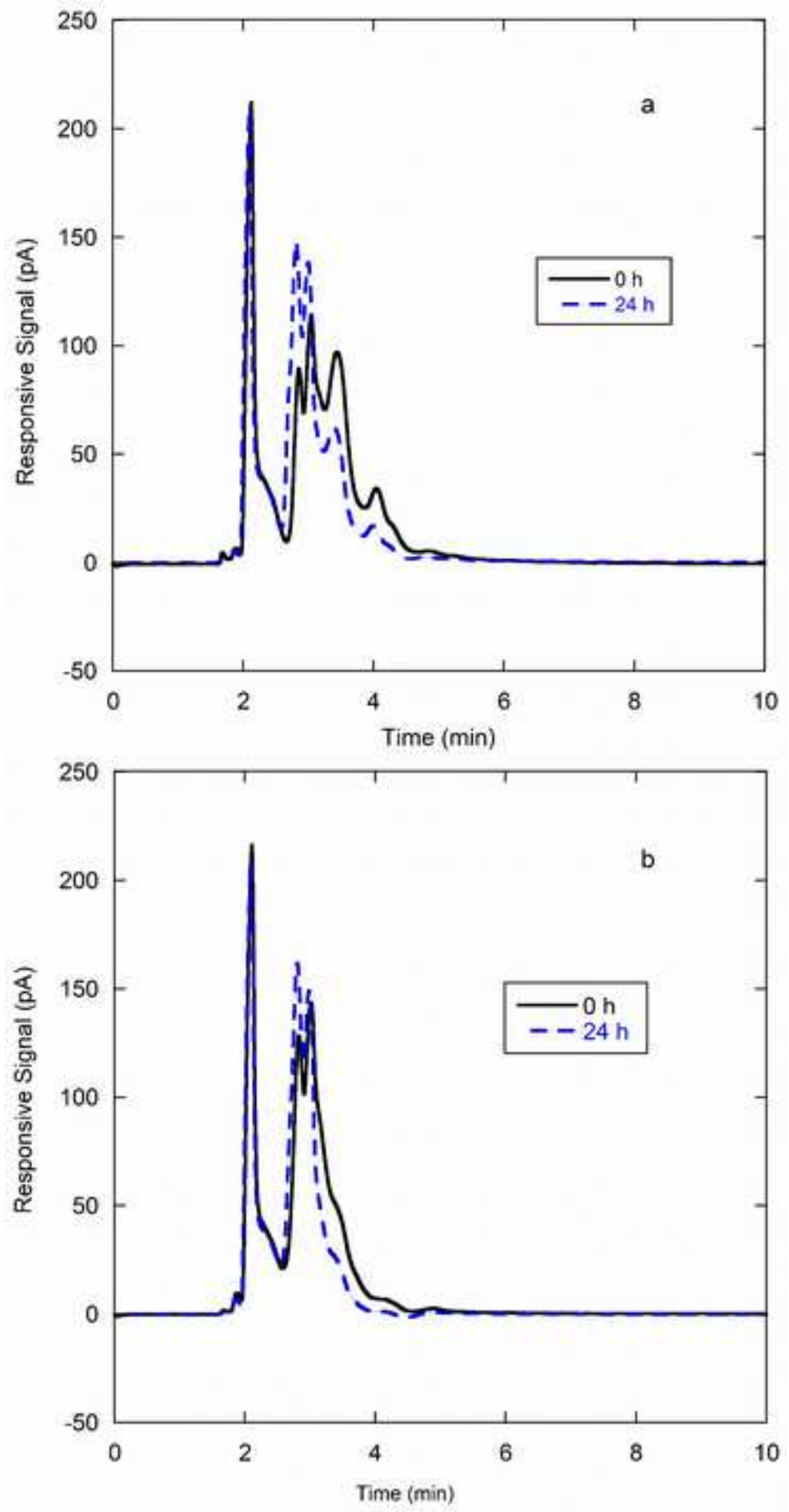


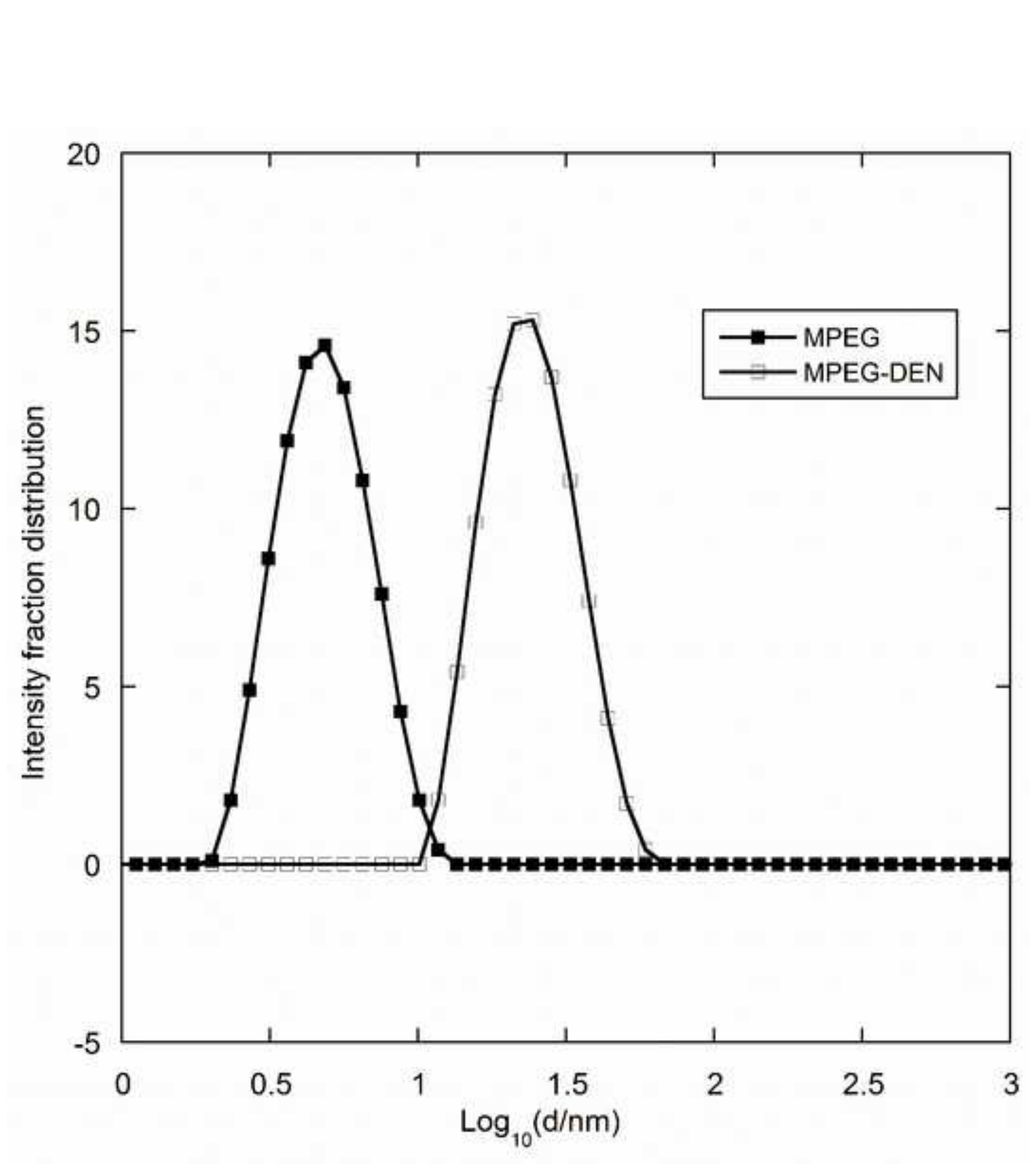

Figure 8

3




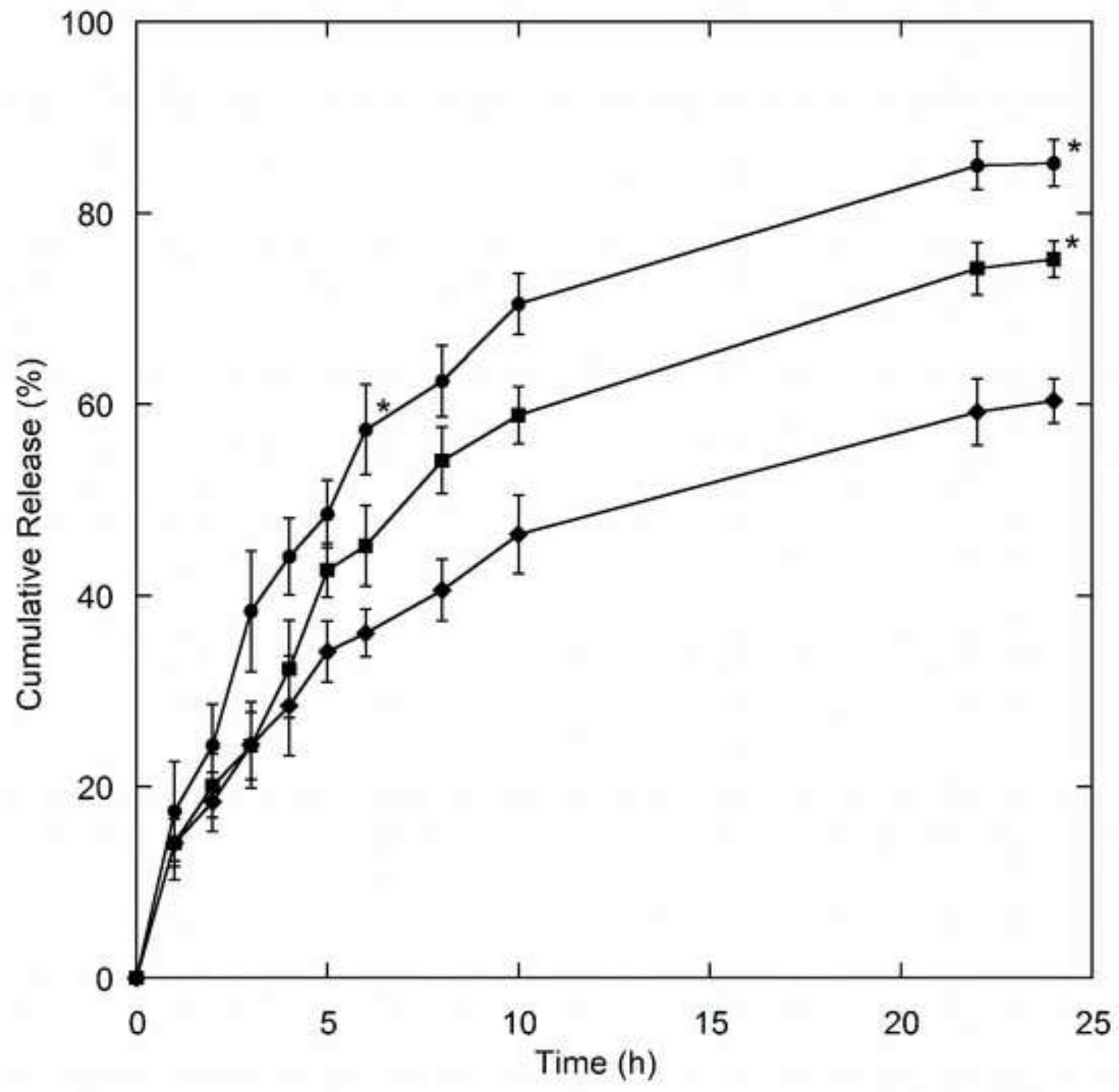

